\title{
Cancers Attributable to Obesity in Indonesia: A Prevalence Based Study Using Disability Adjusted Life Years
}

\author{
Galih Putri Wulandari ${ }^{1} \&$ Susi Ari Kristina ${ }^{1}$ \\ ${ }^{1}$ Faculty of Pharmacy, Universitas Gadjah Mada, Indonesia \\ Correspondence: Susi Ari Kristina, Pharmacy Management dan Community Pharmacy Division, Faculty of \\ Pharmacy, Universitas Gadjah Mada, Indonesia. E-mail: susiari_k@ugm.ac.id
}

Received: May 9, 2018 Accepted: May 28, 2018 Online Published: July 11, 2018

doi:10.5539/gjhs.v10n8p21 URL: https://doi.org/10.5539/gjhs.v10n8p21

\begin{abstract}
The prevalence of obesity in the world has nearly tripled since 1975. Obesity clearly known as risk factor for various diseases, including many types of cancer. This study aims to determine the obesity attributable fraction (OAF) of seven cancers based on the relative risk of esophageal cancer, colorectal, pancreatic, endometrial, ovarian, prostate and kidney cancer and also to estimate the burden of cancer caused by obesity with disability adjusted life years (DALY) indicator. This study is a descriptive epidemiological study with prevalence-based method, which the prevalence data obtained from Indonesian National Health Insurance (BPJS) 2016. The OAF is calculated by combining both data of obesity prevalence and relative risk and the DALY indicator is calculated as the sum of years of life lost due to premature mortality (YLL) and the equivalent healthy years lost due to disability (YLD). Based on OAF calculation, three highest proportions OAF in men were in colorectal cancer (6.02\%), kidney $(4.91 \%)$ and pancreatic cancer $(4.55 \%)$, while in women were from kidney cancer (13.92\%), endometrial $(12.63 \%)$ and colorectal cancer $(7.49 \%)$. Meanwhile the burden priorities of cancer by obesity in Indonesia were come from colon cancer $(23,051)$, ovarian cancer $(21.911)$, and pancreatic cancer $(4,564)$. Burden of cancer attributable to obesity in Indonesia mostly related to digestive organ and high prevalence in female population. It is the impact of life changes and less activity due to globalization. All cancers attributable to obesity should be considered and have to controlled by the government through health programs and policies.
\end{abstract}

Keywords: obesity, cancer, DALY, Indonesia

\section{Introduction}

Obesity is a health problem that is increasing in almost all parts of the world (Rapp et al., 2005). Obesity defined as a condition that indicates an imbalance between body height and body weight due to fatty tissue in the body resulting in excess of weight beyond the ideal value. The most common obesity measurements use a body mass index (BMI), a person's weight in kilograms divided by the square of his height in meters (Centers for Disease Control and Prevention, 2016). According to WHO, a person who has $25-29.9 \mathrm{~kg} / \mathrm{m}^{2}$ of BMI is classified as overweight and someone who has $\geq 30 \mathrm{~kg} / \mathrm{m}^{2}$ of BMI is classified as obese.

According to the WHO report on February 2018, the prevalence of obesity in the world has nearly tripled since 1975. By 2016, there are more than 1.8 billion adults aged $>18$ in the world were classified as overweight and obese. World Obesity Federation estimates that there are 2.7 billion people in the world who will be obese by 2025 . Indonesia is one of the top ten countries with the highest prevalence of obesity in the world (Ng et al., 2014). The results of Indonesia National Basic Health Research in 2013, the prevalence of obesity in the male population was $19.7 \%$, while the prevalence of obesity was $32.9 \%$ of adult females.

Furthermore, the obesity pandemic will continue to increase along with globalization. Increasing socioeconomic status in society leads to changes in lifestyle and lack of activity that affects the onset of obesity (Bhurosy \& Jeewon, 2014). Obesity is a major risk factor for cardiovascular disease, stroke, diabetes, hypertension, musculoskeletal disease and cancer (Park et al., 2006). Besides increasing morbidity, obesity can also increase early mortality, decrease productivity and decrease quality of life (Pitayatienanan et al., 2014). Obesity therefore poses a huge economic burden on individuals, families and countries. By 2014, the global economic impact of obesity was estimated to be US\$2.0 trillion or $2.8 \%$ of global gross domestic product (Tremmel, Gerdtham Ulf-G., Nilsson, \& Saha, 2017). 
Many studies have also reported obesity as being strongly correlated with modification in the physiological function of adipose tissue, which causes insulin resistance, chronic inflammation, and changed adipokine secretion. Some of these factors, such as insulin resistance, increaseded leptin levels, plasminogen-1 activator and endogenous sex steroids inhibitors, made chronic inflammation, also involved in carcinogenesis and cancer metastasis (van Kruijsdijk, van der Wall, \& Visseren, 2009). Weight gain and obesity accounted for about $20 \%$ of all cancer cases (Calle \& Kaaks, 2004). Some cancers associated with obesity include esophageal, thyroid, colon, kidney, liver, melanoma, multiple myeloma, rectal, gallbladder, leukemia, lymphoma, and prostate in men; and breast postmenopausal and endometrial cancer in women (Wolin, Carson, \& Colditza, 2010). Data published over the past 25 years emphasize that obesity responsible for about $20 \%$ of cancer deaths in women and about $14 \%$ in men (De Pergola \& Silvestris, 2013).

Nowadays, the level of awareness of most people about the risk of obesity related to cancer is still low (Bhurosy \& Jeewon, 2014). In fact, the economic burden for the treatment of cancer is a big matter. Therefore, there is a need for intervention to prevent the increased incidence of obesity in order to suppress the occurrence of cancer. Research related to burden of cancer due to obesity in Indonesia not available, so this study is important as consideration of public health promotion using Disability Adjusted Life Years (DALY) indicator developed by WHO and World Bank which calculate disease burden and injury to human population in Global Burden of Disease Study. As an indicator of disease burden, DALY combines estimated life time with disability and time lost due to premature death (Gao, Wang, Chen, Ngo, \& Guo, 2015). This DALY indicator can be used to measure the level of health within a population, establish national policy priorities and evaluate cost-effectiveness of public health interventions (Park et al., 2006).

\section{Methods}

This research was using descriptive epidemiological prevalence-based research design to estimate the burden of cancers due to obesity in Indonesian population. There were four steps to gain the data, first we selected obesity-related cancers from meta-analysis study. Second, we estimated obesity attributable fraction (OAF) using relative risks and prevalence of obesity in Indonesia. Third, we estimated obesity attributable morbidity and mortality from the number of morbidity and mortality multiplied by OAF as the percentage of cancers incidence or mortality attributed to obesity. Fourth, using that analysis result, we calculated the Years Lived with Disability (YLD), Years Life Lost (YLL), and Disability Adjusted Life Years (DALY) values of cancers related to obesity in Indonesia.

\subsection{Selection of Obesity-Related Cancers}

The selection of obesity-related cancers included in this study was based on a systematic review. According to the previous systematic review (Guh et al., 2009) as well as the availability of morbidity and mortality of cancers in Indonesia, we decided to include 7 obesity-related cancer diseases. The prevalence of obesity was obtained from WHO Global Observatory Data 2010 (World Health Organization, 2015b).

\subsection{Estimation of Obesity Attributable Fraction (OAF) of Cancers}

To calculate OAF values due to cancers, two parameters were considered: 1) the relative risks of overweight and obesity for the different related cancers, and 2) prevalence of obesity for male and female. The relative risks for most cancers were obtained from meta-analysis by meta-analysis study of Guh (Guh et al., 2009). The formula of OAF is shown below,

$$
O A F_{j}=\frac{\sum_{i=1}^{2} P_{i}\left(R R_{i j}-1\right)}{\sum_{i=0}^{2} P_{i}\left(R R_{i j}-1\right)+1}
$$

Where:

$i=$ Body Mass Index (BMI) level ( $i=1$ if BMI $\geq 25.0-29.9 \mathrm{~kg} / \mathrm{m}^{2}$ and $i=2$ if BMI $\left.\geq 30 \mathrm{~kg} / \mathrm{m}^{2}\right)$

$j=$ Co morbidity or disease related to obesity $(\mathrm{j}=1-12)$

$\mathrm{P} i \quad=$ Prevalence of obesity based on BMI level

RR $i j=$ Relative risk of co morbidity j related to obesity compared with non-obese Population 


\subsection{Calculation of DALY for Cancer}

To estimate years lived with disability (YLD), input parameters were estimated as follows. First, to estimate the number of incidence and mortality of cancers by age, we used the Indonesian health assurance system, 2016 which projected into GLOBOCAN data in the current year (2012) (International Agency for Research on Cancer, 2012). Second, to estimate disability weight of each cancer, we used a recent study conducted in Korea (Choi, Park, \& Lee, 2013) which is predicted had similar characteristics among Asia Pacific population. Third, we measured duration of selected types of cancers by using DISMOD II software developed by WHO (World Health Organization, 2015a).

Under the DISMOD II model, it is assumed that any individual or group that is susceptible to a specific cancer at a certain point in time will trigger the incidence of the cancer as they become infected. It is also assumed that the remission of all cancers is not occurred. The fourth, we calculated YLD from the number of obesity related cancer incidence, duration, and disability weight. To estimate years life lost (YLL), we used WHO standard expected years of life in 2012 (World Health Organization, 2012) to calculate the years of prematurely death. To estimate age-specific YLL we applied the YLL formula as number of obesity attributable deaths multiplied by number of years remaining to lives. To determine DALY values, we summed YLD with YLL results.

$$
\mathrm{DALY}=\mathrm{YLL}+\mathrm{YLD}
$$

\section{Results}

Obesity attributable fraction (OAF) shows the proportion of cancer incidence or mortality rates due to obesity. OAF values range from $0-1$, which 0 has meaning that obesity has no association to the onset of the disease, while 1 has meaning that obesity totally associated to the incidence of the disease. Table 1 shows that the three most common cancers due to obesity in males were colorectal cancer $(6.02 \%)$, kidney cancer $(4.91 \%)$ and pancreatic cancer $(4.55 \%)$, whereas in female came from kidney cancer $(13.92 \%)$, uterine cancer $(12.63 \%)$ and colorectal cancer $(7.49 \%)$.

Table 1. Relative risks and OAFs for selected cancers in Indonesia

\begin{tabular}{|c|c|c|c|c|c|c|c|c|c|c|}
\hline \multirow{3}{*}{ Cancer } & \multicolumn{4}{|c|}{ Relative risks } & \multicolumn{4}{|c|}{ OAF(\%) } & \multirow{2}{*}{\multicolumn{2}{|c|}{$\mathrm{OAF}(\%)$}} \\
\hline & \multicolumn{2}{|c|}{ Overweight } & \multicolumn{2}{|c|}{ Obese } & \multicolumn{2}{|c|}{ Overweight } & \multicolumn{2}{|c|}{ Obese } & & \\
\hline & Male & Female & Male & Female & Male & Female & Male & Female & Male & Female \\
\hline Esophagus & 1.13 & 1.15 & 1.21 & 1.20 & 2.51 & 3.88 & 0.65 & 1.30 & 1.58 & 2.59 \\
\hline Colorectum & 1.51 & 1.45 & 1.95 & 1.66 & 9.17 & 10.80 & 2.86 & 4.17 & 6.02 & 7.49 \\
\hline Pancreas & 1.28 & 1.24 & 2.29 & 1.60 & 5.25 & 6.06 & 3.85 & 3.81 & 4.55 & 4.94 \\
\hline Uterine & 0 & 1.53 & 0 & 3.22 & 0 & 12.48 & 0 & 12.78 & 0 & 12.63 \\
\hline Ovary & 0 & 1.18 & 0 & 1.28 & 0 & 4.62 & 0 & 1.81 & 0 & 3.22 \\
\hline Prostate & 1.14 & 0 & 1.05 & 0 & 2.70 & 0 & 0.15 & 0 & 1.43 & 0 \\
\hline Kidney & 1.40 & 1.82 & 1.85 & 2.64 & 7.34 & 18.07 & 2.4 & 9.77 & 4.91 & 13.92 \\
\hline
\end{tabular}

The data on morbidity and mortality of cancer in Indonesia due to obesity are presented in Table 2 . The table shows that the amount of morbidity due to obesity cancer was 2.682 cases while the number of cancer deaths due to obesity of 1.908 persons, which $65 \%$ of cancer patients are women and cause $71 \%$ of mortality. 
Table 2. Obesity attributable morbidity and mortality for selected cancers in Indonesia

\begin{tabular}{|c|c|c|c|c|c|c|c|c|}
\hline \multirow[t]{2}{*}{ Cancers } & \multicolumn{2}{|c|}{ Cancer morbidity } & \multicolumn{2}{|c|}{$\begin{array}{l}\text { Cancer Morbidity attributable } \\
\text { obesity }\end{array}$} & \multicolumn{2}{|c|}{$\begin{array}{l}\text { Cancer } \\
\text { mortality }\end{array}$} & \multicolumn{2}{|c|}{$\begin{array}{l}\text { Cancer Mortality attributable } \\
\text { obesity }\end{array}$} \\
\hline & Male & Female & Male & Female & Male & Female & Male & Female \\
\hline Esophagus & 288 & 145 & 9 & 8 & 265 & 135 & 9 & 7 \\
\hline Colorectum & 5,204 & 4,636 & 626 & 695 & 3,429 & 3,083 & 413 & 462 \\
\hline Pancreas & 1,013 & 899 & 92 & 89 & 984 & 867 & 90 & 86 \\
\hline Uterine & 0 & 36 & 0 & 9 & 0 & 11 & 0 & 2 \\
\hline Ovary & 0 & 12,274 & 0 & 790 & 0 & 8,514 & 0 & 547 \\
\hline Prostate & 5,221 & 0 & 149 & 0 & 3,512 & 0 & 100 & 0 \\
\hline Kidney & 764 & 505 & 75 & 140 & 564 & 492 & 55 & 137 \\
\hline Total & 12,490 & 18,495 & 951 & 1,731 & 8,754 & 13,102 & 667 & 1,241 \\
\hline
\end{tabular}

The three most frequent of cancers caused by obesity in men were colorectal cancer 626 cases, 149 for prostate cancer and 92 for pancreatic cancer. Meanwhile in women, 790 cases came from ovarian cancer, 695 from colorectal cancer and 140 from kidney cancer. The three most common obesity related cancers that cause death in men were colorectal cancer (413 persons), prostate cancer (100 persons) and pancreatic cancer ( 90 persons). While in women were ovarian cancer ( 547 persons), colorectal cancer (462 persons) and kidney cancer (137 persons).

Table 3. YLD, YLL, DALY for obesity-related cancer

\begin{tabular}{|c|c|c|c|c|c|c|c|c|c|}
\hline \multirow[t]{2}{*}{ Cancer } & \multicolumn{3}{|c|}{$\begin{array}{l}\text { Years lived with disability } \\
\text { (YLD) }\end{array}$} & \multicolumn{3}{|c|}{$\begin{array}{l}\text { Years of life lost due to premature } \\
\text { death (YLL) }\end{array}$} & \multicolumn{3}{|c|}{$\begin{array}{l}\text { Disability-adjusted life years } \\
\text { (DALY) }\end{array}$} \\
\hline & Male & Female & Total & Male & Female & Total & Male & Female & Total \\
\hline Esophagus & 73 & 73 & 146 & 133 & 111 & 244 & 206 & 184 & 390 \\
\hline Colorectum & 4,668 & 4,358 & 9,026 & 6,220 & 7,805 & 14,025 & 10,888 & 12,163 & 23,051 \\
\hline Pancreas & 912 & 1,021 & 1,933 & 1,320 & 1,311 & 2,631 & 2,332 & 2,332 & 4,564 \\
\hline Uterine & 0 & 26 & 26 & 0 & 45 & 45 & 0 & 71 & 71 \\
\hline Ovary & 0 & 10,174 & 10,174 & 0 & 11,737 & 11,737 & 0 & 21,911 & 21,911 \\
\hline Prostate & 403 & 0 & 403 & 847 & 0 & 847 & 1,250 & 0 & 1,250 \\
\hline Kidnye & 330 & 684 & 1,014 & 860 & 2,046 & 2,906 & 1,190 & 2,730 & 3,920 \\
\hline Total & 6386 & 16,336 & 22,722 & 9,380 & 23,055 & 23,993 & 7,324 & 39,391 & 46,715 \\
\hline
\end{tabular}

Table 3 shows the number of year's life lost due to disability (YLD) and early death (YLL). By multiplying the rate of cancer incidence due to obesity, disability weight and duration of disease, the value of YLD obtained. The highest YLD in males were colorectal cancer (4,668 person years), pancreatic cancer (912 PY), and prostate cancer (403 PY). While in women, the three highest YLD were come from ovary cancer (10,174 PY), colorectal cancer (4,358 PY) and pancreatic cancer (1,021 PY). In addition, the highest YLL in males is colorectal cancer (6,220 PY), pancreatic cancer (1,320 PY) and kidney cancer (860 PY). While in women were ovarian cancer (11,737 PY), colorectal cancer (7,805 PY) and pancreatic cancer (1,311 PY). Furthermore, the burden of cancer due to obesity in Indonesia with the highest DALY in men was colorectal cancer (10,888 PY), pancreas cancer (2,332 PY) and prostate cancer (1250 PY), while in women were ovary cancer (21,911 PY), colorectal cancer (12,163 PY) and kidney cancer (2,730 PY). From Table 3, it can be concluded that the burden priorities for obesity related cancer in Indonesia in both men and women were from colorectal cancer 23,051 PY, ovarian cancer 21,911 PY, and pancreatic cancer 4,564 PY.

\section{Discussion}

From this study, it was found that the burden of cancer due to obesity is greater in women than in men. This is 
directly proportional to the magnitude of the prevalence of obesity and also the relative risks are higher in women. The greater relative risks, resulted on the greater value of obesity lead to cancer.

This study shows that obesity has a considerable effect on the onset of most cancers in the digestive system. This is influenced by some of mechanisms like; first obesity is related to the amount of adipose in the body. Not only as lipid storage, adipose tissue now known as a very active endocrine organ (Kershaw \& Flier, 2004). Adipose tissue contains adipocytes and vascular stromal tissues containing pre-adipocytes, some types of endothelial cells, and macrophages (Trayhurn, 2007). These contents will release many products that will enter the circulatory system and have effects on other tissue. Products released are including adipokines (leptin and adiponectin) and cytokines (alpha-factor necrosis factor, interleukin-6 and plasminogen activator inhibitor-1) which involved in the modulation of cancer risk (Dethlefsen, Hojfeldt, \& Hojman, 2013; Guo et al., 2013). In addition, obesity has consequences on the occurrence of insulin resistance that can cause changes in the circulation of insulin. These changes have an effect on cellular proliferation and inhibit apoptosis, and have been associated with several types of cancers (Calle \& Kaaks, 2004).

Obesity is very influential on the incidence of colon cancer. This is due to the lack of physical activity and unhealthy lifestyles that become powerful triggers of colon cancer. When a person has regular physical activity and healthy diet, it will help to lower the risk of colon cancer (Bazensky, Shoobridge-Moran, \& Yoder, 2007). Physical activity will also increase the metabolic rate and lead to optimum oxygen uptake (de Jong et al., 2005). In the long duration, regular activity can increase the body's metabolic capacity; lower blood pressure and insulin resistance (Lee et al., 2007).

Research on cancer attributable to obesity has been done in several countries in the world. First, research in China performed by Wang (Wang D et al., 2012) conducted in 2005, reported there was $0.65 \%$ incidence of cancer due to obesity and $0.32 \%$ experience death. Second, research in Australia conducted by Kendall et al. (2015) showed there were 3,917 cancers diagnosed in 2010 related with obesity and gives a result that $28 \%$ or 1,101 were colon cancer. Furthermore, research in US and UK conducted by Wang et al. (Wang, McPherson, Marsh, Gortmaker, \& Brown, 2011) projected that cancer cases will be increased by 492,000 - 669,000 in 2030 which associated with obesity. Cancer research with DALY measurement performed in India by Murthy (2010) reported DALY for colon cancer was 79,065 in the men population and 69,856 in female in 2011 (Murthy, Nandakumar, Pruthvish, George, \& Mathew, 2010). Then, the study also projected by 2016, DALY for colon were increase by 121,043 in the male population and 110,850 in female. In addition, the burden of cancer in ASEAN member countries with DALY has also been done by Kimman et al. (Kimman, Norman, Jan, Kingston, \& Woodward, 2012), mentioned that one of cancers type which often be the cause of death is colon cancer as many as 44,280 DALY.

The economic burden of cancer due to obesity has also been done in several countries in the world. First, a Canadian study conducted by Krueger et al. (Krueger, Andres, Koot, \& Reilly, 2016) shows that the annual economic burden of cancer due to some risk factors was $\$ 9.6$ billion, which $\$ 1.7$ billion is direct cost and $\$ 8.0$ is an indirect cost. Furthermore, Wang's (2011) study in US and UK estimates that the medical costs of obesity related cancers can increase by $\$ 48-66$ billion/year in the USA and by $£ 1.9-2$ billion/year in UK 2030 . Therefore, this research is useful as a consideration of the policy of controlling the incidence of obesity, so that the economic burden of the government will not so high. This study has several limitations. First, the research is limited only for seven cancers. Second, the available morbidity and mortality data in BPJS 2016 only covers about 80 percent of total population in Indonesia.

\section{Conclusions}

Burden of cancer attributable to obesity in Indonesia mostly related to digestive organ and high prevalence in female population. It is the impact of life changes and less activity due to globalization. All cancers attributable to obesity should be considered and have to controlled by the government through health programs and policies.

\section{Acknowledgements}

We thank National Bureau of Universal Health Coverage for providing database of cancers incidence and Faculty of Pharmacy, Universitas Gadjah Mada for funding support of this research.

\section{Competing Interests Statement}

The authors declare that there are no competing or potential conflicts of interest.

\section{References}

Bazensky, I., Shoobridge-Moran, C., \& Yoder, L. H. (2007). Colorectal cancer: An overview of the epidemiology, risk factors, symptoms, and screening guidelines. Medsurg Nursing Journal, 16(1), 46-51. 
Bhurosy, T., \& Jeewon, R. (2014). Overweight and obesity epidemic in developing countries: A problem with diet, physical activity, or socioeconomic status? Scientific World Journal, 2014, 964236. https://doi.org/10.1155/2014/964236

Calle E. E., \& Kaaks R. (2004). Overweight, obesity and cancer: Epidemiological evidence and proposed mechanisms. Nature Reviews Cancer, 4(8), 579-591. https://doi.org/10.1038/nrc1408

Centers for Disease Control and Prevention. (2016). Overweight \& Obesity: Defining Adult Overweight and Obesity. United States.

Choi, K. S., Park, J. H., \& Lee, K. S. (2013). Disability weights for cancers in Korea. Journal of Korean Medical Science, 28, 808-813. https://doi.org/10.3346/jkms.2013.28.6.808

De Jong, A. E., Morreau, H., Nagengast, F. M., Mathus-Vliegen, E. M., Kleibeuker, J. H., Griffioen, G., ... \& Vasen, H. F. (2005). Prevalence of adenomas among young individuals at average risk for colorectal cancer. The American journal of gastroenterology, 100(1), 139. https://doi.org/10.1111/j.1572-0241.2005.41000.x

De Pergola, G., \& Silvestris, F. (2013). Obesity as a major risk factor for cancer. Journal of Obesity, 291546. https://doi.org/10.1155/2013/291546

Dethlefsen, C., Hojfeldt, G., \& Hojman, P. (2013). The role of intratumoral and systemic IL-6 in breast cancer. Breast Cancer Research and Treatment, 138(3), 657-664. https://doi.org/10.1007/s10549-013-2488-z

Gao T, Wang XC, Chen R, Ngo HH, \& Guo W. (2015). Disability adjusted life year (DALY): A useful tool for quantitative assessment of environmental pollution. Science of the Total Environment, 11, 268-287. https://doi.org/10.1016/j.scitotenv.2014.11.048

Guh, D. P., Zhang, W., Bansback, N., Amarsi, Z., Birmingham, C. L., \& Anis, A. H. (2009). The incidence of co-morbidities related to obesity and overweight: A systematic review and meta-analysis. BioMed Central Pub Health, 9(88). https://doi.org/10.1186/1471-2458-9-88

Guo, X. F., Wang, J., Yu, S. J., Song, J., Ji, M. Y., Cao, Z., . . Dong, W. G. (2013). TNF-Alpha-308 polymorphism and risk of digestive system cancers: A meta-analysis. World Journal of Gastroenterology, 19(48), 9461-9471. https://doi.org/10.3748/wjg.v19.i48.9461

International Agency for Research on Cancer. (2012). GLOBOCAN 2012: Estimated Cancer Incidence, Mortality, and Prevalence Worldwide 2012. Geneva.

Kendall, B. J., Wilson, L. F., Olsen, C. M., Webb, P. M., Neale, R. E., Bain, C. J., \& Whiteman, D. C. (2015). Cancers in Australia in 2010 attributable to overweight and obesity. Aust NZ J Public Health, 39(5), 452-457. https://doi.org/10.1111/1753-6405.12458

Kershaw, E. E., \& Flier, J. S. (2004). Adipose tissue as an endocrine organ. The Journal of Clinical Endocrinology and Metabolism, 89(6), 2548-2556. https://doi.org/10.1210/jc.2004-0395

Kimman, M., Norman, R., Jan, S., Kingston, D., \& Woodward, M. (2012). The burden of cancer in member countries of the Association of Southeast Asian Nations (ASEAN). Asian Pacific Journal of Cancer Prevention, 13, 411-420. https://doi.org/10.7314/APJCP.2012.13.2.411

Krueger, H., Andres, E. N., Koot, J. M., \& Reilly, B. D. (2016). The economic burden of cancers attributable to tobacco smoking, excess weight, alcohol use, and physical inactivity in Canada. Current Oncology, 23(4), 241-249. https://doi.org/10.3747/co.23.2952

Lee, K. J., Inoue, M., Otani, T., Iwasaki, M., Sasazuki, S., Tsugane, S., \& et al. (2007). Physical activity and risk of colorectal cancer in Japanese men and women: The Japan Public Health Center-based prospective study. Cancer Causes Control, 18(2), 199-209. https://doi.org/10.1007/s10552-006-0098-3

Murthy, N. S., Nandakumar, B. S., Pruthvish, S., George, P. S., \& Mathew, A. (2010). Disability adjusted life years for cancer patients in India. Asian Pacific Journal of Cancer Prevention, 11, 633-640.

Ng, M., Fleming, T., Robinson, M., Thomson, B., Graetz, N., Margono, C., . . Gakidou, E. (2014). Global, regional, and national prevalence of overweight and obesity in children and adults during 1980-2013: A systematic analysis for the Global Burden of Disease Study 2013. Lancet, 384(9945), 766-781. https://doi.org/10.1016/S0140-6736(14)60460-8

Park JH, Yoon SJ, Lee H, Jo HS, Lee SI, Kim Y, . . Shin Y. (2006). Burden of disease attributable to obesity and overweight in Korea. International Journal of Obesity (London), 30(11), 1661-1669. https://doi.org/10.1038/sj.ijo.0803321 
Pitayatienanan, P., Butchon, R., Yothasamut, J., Aekplakorn, W., Teerawattananon, Y., Suksomboon, N., \& Thavorncharoensap, M. (2014). Economic costs of obesity in Thailand: A retrospective cost-of-illness study. BMC Health Services Research, 14, 146. https://doi.org/10.1186/1472-6963-14-146

Rapp, K., Schroeder, J., Klenk, J., Stoehr, S., Ulmer, H., Concin, H., . . . Weiland, S. K. (2005). Obesity and incidence of cancer: A large cohort study of over 145000 adults in Austria. British Journal of Cancer, 93, 1062-1067. https://doi.org/10.1038/sj.bjc.6602819

Trayhurn, P. (2007). Adipocyte biology. Obesity Reviews, 8. https://doi.org/10.1111/j.1467-789X.2007.00316.x

Tremmel, M., Gerdtham, Ulf-G., Nilsson, P. M., \& Saha, S. (2017). Economic burden of obesity: A systematic literature review. International Journal of Environmental Research and Public Health, 14(4), 435. https://doi.org/10.3390/ijerph14040435

van Kruijsdijk, R. C. M., van der Wall, E., \& Visseren, F. L. J. (2009). Obesity and cancer: The role of dysfunctional adipose tissue. Cancer Epidemiology, Biomarkers and Prevention, 18(10), 2569-2578. https://doi.org/10.1158/1055-9965.EPI-09-0372

Wang, D., Zheng, W., Wang, S.-M., Wang, J.-B., Wei, W.-Q., Liang, H., . . Boffetta, P. (2012). Estimation of cancer incidence and mortality attributable to overweight, obesity, and physical inactivity in China. Nutr Cancer, 64(1), 48-56. https://doi.org/10.1080/01635581.2012.630166

Wang, Y. C., McPherson, K., Marsh, T., Gortmaker, S. L., \& Brown, M. (2011). Health and economic burden of the projected obesity trends in the USA and the UK. Lancet, 378, 815-825. https://doi.org/10.1016/S0140-6736(11)60814-3

Wolin, K. Y., Carson, K., \& Colditza, G. A. (2010). Obesity and cancer. The Oncologist, 15(6), $556-565$. https://doi.org/10.1634/theoncologist.2009-0285

World Health Organization. (2012). Life Tables 2012. Geneva: WHO.

World Health Organization. (2015a). Health Statistics and Information Systems: DISMOD II Software Tool. Geneva: WHO.

World Health Organization. (2015b). Prevalence of Obesity, Ages 18+, 2010-2014 (Age Standardized Estimate). Geneva: WHO.

\section{Copyrights}

Copyright for this article is retained by the author(s), with first publication rights granted to the journal.

This is an open-access article distributed under the terms and conditions of the Creative Commons Attribution license (http://creativecommons.org/licenses/by/4.0/). 